\title{
Viscometric Study of S-Substituted Triazinothioureas at Various Compositions
}

\author{
M. S. Lunge. \\ Department of Chemistry. Government Vidharbha Institute of Science and Humanities,Amravati (M.S.) Pin- \\ 444 604, India.
}

\begin{abstract}
Nitrogen and sulphur containing heterocycles have much more significance in drug, pharmaceutical and medicinal chemistry since from last four decades. Hence, the viscometric study of recently synthesized heterocycles viz. 1-(4-hydroxy)-S-triazino-3-p-chlorophenyl- thiourea $\left(L_{1}\right), 1-(4-h y d r o x y)-S$-triazino-3allylthiourea $\left(L_{2}\right)$ and 1-(4-hydroxy)-S-triazino-3-t-butylturea $\left(L_{3}\right)$, were carried out at various percentage compositions of solvent to investigate effect of structure, group on S-triazinothiourea, The data and result obtained during this investigation is useful in pharmokinetics and pharmodynamics. Taking all these things into consideration this research work was carried out.
\end{abstract}

Keywords: 1-(4-Hydroxy)-S-triazino-3-substitutedthiourea, dioxane-water, viscometric study.

\section{Introduction:}

Viscosities of the solution play an important role in pharmaceutical, medicinal and drug chemistry. ${ }^{1-3}$ Solute -solute, solute-solvent, solvent-solvent interactions in drug chemistry were studies by viscometric information. Hence, taking all these things into consideration and as wider programmee of this laboratory in the synthesis of nitrogen, sulphur and nitrogen and sulphur containing heteroacycles and heterocycles, it was thought interesting to carry out the viscometric study of newly synthesized heterocycles in this laboratory. This study explores the potency of synthesized drug, stability of drug and also renovates and modifies the traditional drugs which are used by medicinal practitioner.

The pharmaceutical and medicinal literature survey clearly indicated that newly synthesized drugs are the best for particular diseases but after some time interval, the drug effect and their activities become less and those drugs became out dated for that disease, due to continuous evolutions in the pathogens. It was observed that in the universe these pathogens have a great and rapid evolutionary phenomenon and the drug become food for those pathogens. |It become challenge to chemist and researchers to synthesized new type drugs for old diseases.

S-Triazino and thiourea nucleus containing drugs create its own identity and significance in drug and pharmaceutical chemistry ${ }^{4-10}$ Hence for studying the potency of recently synthesized drugs in this laboratory, the viscosity study of 1-(4-hydroxy)-S-triazino-3-p-chlorophenylthiourea $\left(\mathrm{L}_{1}\right)$,1-(4-hydroxy)-S-triazino-3allylthiourea $\left(\mathrm{L}_{2}\right)$ and 1-(4-hydroxy)-S-triazino-3-t-butylthiourea $\left(\mathrm{L}_{3}\right)$,were studied at various percentage compositions. This study becomes milestone in the drug medicinal, pharmaceutical of triazinothiourea.

\section{Experimental:}

All the chemicals used of A.R grade and doubly distilled water was used. Weighing was made on Mechaniki Zaktady Precyzyjnej Gdansk balance made in Poland ( $\pm 0.001 \mathrm{gm})$.Densities of solutions were determined by a bicapillary pyknometer $( \pm 0.2 \%)$ having a bulb volume of about $10 \mathrm{~cm}^{3}$ and capillary having an internal diameter of $1 \mathrm{~mm}$ and calibrated with deionised doubly distilled water. The accuracy of density measurements were within $\pm 0.1 \mathrm{Kgm}^{-3}$. The viscosities were measured by means of Ostwald's viscometer thoroughly cleaned and dried. The viscometer was kept in Elite thermostatic water bath and temperature variation was maintained at $30{ }^{\circ} \mathrm{C}( \pm 0.1)$ for each measurements, sufficient time was allowed to attain thermal equilibrium between viscometer and water bath.

\section{Observations and calculations:}

The present study deals with the viscosity investigation of Ligand $\left(\mathrm{L}_{1}\right)$, Ligand $\left(\mathrm{L}_{2}\right)$, Ligand $\left(\mathrm{L}_{3}\right)$ in $65 \%, 75 \%$ and $85 \%$ dioxane -water mixture at different compositions and at $303.15 \mathrm{~K}\left(30^{\circ} \mathrm{C}\right)$. The data obtained have been used to compute molecular interactions in terms if $\beta$-coefficient of different ligands. The viscometric readings were taken as described in literature ${ }^{11}$.The results obtained was mentioned in Table No, 19.

According to Jone's-Dole equation, $(\eta r-1) \sqrt{ } \mathrm{C}=\mathrm{A}+\beta \sqrt{\mathrm{C}}$ at different concentration and different percentage. and $\beta$-coefficient values calculated and are enlisted in Table No 10-12. 


\section{Determination of Relative and Specific Viscosities at Different Concentrations}

\section{A] For Ligand $\mathbf{L}_{1}$}

Table No 1:- Dioxane-water (65\%)

Temp-(303.15 K) System $\mathrm{L}_{1}$,

Medium: - Dioxane-water

\begin{tabular}{|c|c|c|c|c|c|c|}
\hline Conc. & $\sqrt{ } \mathrm{C}$ & $\begin{array}{c}\text { Time flow } \\
(\mathrm{sec}) \mathrm{t}\end{array}$ & $\begin{array}{c}\text { Density } \\
\times 10^{3}\end{array}$ & $\begin{array}{c}\eta_{\mathrm{r} \text { Relative }} \\
\text { viscosity }\end{array}$ & $\begin{array}{c}\eta_{\mathrm{sp}}=\eta \mathrm{r}-1 \\
\text { specific } \\
\text { Viscosity }\end{array}$ & $\eta_{\mathrm{r}}-1 / \sqrt{ } \mathrm{C}$ \\
\hline 0.1 & 0.31633 & 376 & 1.0243 & 1.5535 & 0.5532 & 1.74848 \\
\hline 0.075 & 0.27394 & 364 & 1.0241 & 1.4991 & 0.4990 & 1.81997 \\
\hline 0.056 & 0.23673 & 349 & 1.0237 & 1.4408 & 0.4408 & 1.86024 \\
\hline 0.042 & 0.20502 & 340 & 1.0234 & 1.3993 & 0.3992 & 1.94504 \\
\hline
\end{tabular}

Table No2:- Dioxane-water (75\%)

Temp-(303.15 K) System $\mathrm{L}_{1}$,

Medium:- Dioxane-water

\begin{tabular}{|c|c|c|c|c|c|c|}
\hline Conc. & $\sqrt{ } \mathrm{C}$ & $\begin{array}{c}\text { Time flow } \\
(\mathrm{sec}) \mathrm{t}\end{array}$ & $\begin{array}{c}\text { Density } \\
\times 10^{3}\end{array}$ & $\begin{array}{c}\eta_{\text {r Relative }} \\
\text { viscosity }\end{array}$ & $\begin{array}{c}\eta_{\text {sp }} \eta_{\mathrm{r}-1} \\
\text { specific } \\
\text { Viscosity }\end{array}$ & $\eta_{\mathrm{r}}-1 / \sqrt{\mathrm{C}}$ \\
\hline 0.1 & 0.31630 & 401 & 1.0294 & 1.4184 & 0.4184 & 1.32126 \\
\hline 0.075 & 0.27393 & 392 & 1.0287 & 1.3796 & 0.3796 & 1.38397 \\
\hline 0.056 & 0.23671 & 379 & 1.0278 & 1.3343 & 0.3344 & 1.41020 \\
\hline 0.042 & 0.20501 & 369 & 1.0263 & 1.2974 & 0.2973 & 1.44781 \\
\hline
\end{tabular}

Table No3:- Dioxane-water (85\%)

Temp-(303.15 K) System $\mathrm{L}_{1}$,

Medium: - Dioxane-water

\begin{tabular}{|c|c|c|c|c|c|c|}
\hline Conc. & $\sqrt{ } \mathrm{C}$ & $\begin{array}{c}\text { Time flow } \\
(\mathrm{sec}) \mathrm{t}\end{array}$ & $\begin{array}{c}\text { Density } \\
\times 10^{3}\end{array}$ & $\begin{array}{c}\eta_{\text {r Relative }} \\
\text { viscosity }\end{array}$ & $\begin{array}{c}\eta_{\text {sp }=\eta \mathrm{r}-1} \\
\text { specific } \\
\text { Viscosity }\end{array}$ & $\eta_{\mathrm{r}}-1 / \sqrt{\mathrm{C}}$ \\
\hline 0.1 & 0.31630 & 419 & 1.0320 & 1.3809 & 0.3809 & 1.20267 \\
\hline 0.075 & 0.27393 & 408 & 1.0299 & 1.3418 & 0.3418 & 1.24591 \\
\hline 0.056 & 0.23671 & 398 & 1.0287 & 1.3059 & 0.3059 & 1.29019 \\
\hline 0.042 & 0.20502 & 390 & 1.0271 & 1.2796 & 0.2796 & 1.36144 \\
\hline
\end{tabular}

\section{B] For Ligand $\mathrm{L}_{2}$}

Table No 4:- Dioxane-water (65\%)

Temp-(303.15 K) System $\mathrm{L}_{2}$,

Medium: - Dioxane-water

\begin{tabular}{|c|c|c|c|c|c|c|}
\hline Conc. & $\sqrt{ } \mathrm{C}$ & $\begin{array}{c}\text { Time flow } \\
(\mathrm{sec}) \mathrm{t}\end{array}$ & $\begin{array}{c}\text { Density } \\
\times 10^{3}\end{array}$ & $\begin{array}{c}\eta_{\mathrm{r} \text { Relative }} \\
\text { viscosity }\end{array}$ & $\begin{array}{c}\eta \mathrm{sp}=\eta \mathrm{r}-1 \\
\text { specific } \\
\text { Viscosity }\end{array}$ & $\eta_{\mathrm{r}}-1 / \sqrt{ } \mathrm{C}$ \\
\hline 0.1 & 0.31630 & 398 & 1.03398 & 1.6614 & 0.6614 & 2.08939 \\
\hline 0.075 & 0.27393 & 381 & 1.02951 & 1.5824 & 0.5824 & 2.12450 \\
\hline 0.056 & 0.23671 & 377 & 1.02617 & 1.5223 & 0.5223 & 2.20423 \\
\hline 0.042 & 0.20501 & 354 & 1.02187 & 1.4700 & 0.4700 & 2.29002 \\
\hline
\end{tabular}

TableNo5:- Dioxane-water (75\%)

Temp-(303.15 K) System $\mathrm{L}_{2}$, $\quad$ Medium:- Dioxane-water

\begin{tabular}{|c|c|c|c|c|c|c|}
\hline Conc. & $\sqrt{ } \mathrm{C}$ & $\begin{array}{c}\text { Time flow } \\
(\mathrm{sec}) \mathrm{t}\end{array}$ & $\begin{array}{c}\text { Density } \\
\times 10^{3}\end{array}$ & $\begin{array}{c}\eta_{\mathrm{r} \text { Relative }} \\
\text { viscosity }\end{array}$ & $\begin{array}{c}\eta_{\mathrm{sp}=} \eta_{\mathrm{r}-1} \\
\text { specific } \\
\text { Viscosity }\end{array}$ & $\eta_{\mathrm{r}}-1 / \sqrt{ } \mathrm{C}$ \\
\hline 0.1 & 0.31630 & 431 & 1.03506 & 1.5321 & 0.5321 & 1.68049 \\
\hline 0.075 & 0.27393 & 413 & 1.03108 & 1.4624 & 0.4624 & 1.68593 \\
\hline 0.056 & 0.23671 & 402 & 1.02597 & 1.4190 & 0.4190 & 1.76771 \\
\hline 0.042 & 0.20502 & 396 & 1.02079 & 1.3884 & 0.3884 & 1.89234 \\
\hline
\end{tabular}


Table No 6:- Dioxane-water $(85 \%)$

Temp-(303.15 K) System $\mathrm{L}_{2}$,

Medium: - Dioxane-water

\begin{tabular}{|l|l|l|l|l|l|l|}
\hline Conc. & $\sqrt{ } \mathrm{C}$ & $\begin{array}{l}\text { Time flow } \\
(\mathrm{sec}) \mathrm{t}\end{array}$ & $\begin{array}{l}\text { Density } \\
\times 10^{3}\end{array}$ & $\begin{array}{l}\eta_{\mathrm{r}} \text { Relative } \\
\text { viscosity }\end{array}$ & $\begin{array}{l}\eta_{\mathrm{sp}=} \eta_{\mathrm{r}-1} \\
\text { specific } \\
\text { Viscosity }\end{array}$ & $\eta_{\mathrm{r}}-1 / \sqrt{\mathrm{C}}$ \\
\hline 0.1 & 0.31630 & 423 & 1.0362 & 1.4074 & 0.4074 & 1.28617 \\
\hline 0.075 & 0.27393 & 420 & 1.0320 & 1.3840 & 0.3841 & 1.31004 \\
\hline 0.056 & 0.23671 & 413 & 1.0268 & 1.3603 & 0.3603 & 1.52092 \\
\hline 0.042 & 0.20500 & 403 & 1.0232 & 1.3241 & 0.3241 & 1.57810 \\
\hline
\end{tabular}

C] For Ligand $L_{3}$

TableNo7:-Dioxane-water (65\%)

\begin{tabular}{|c|c|c|c|c|c|c|}
\hline Temp-(303.15 K) & \multicolumn{2}{|c|}{ System $\mathrm{L}_{3}$, } & \multicolumn{3}{|c|}{ Medium: - Dioxane-water } & \\
\hline Conc. & $\sqrt{ } \mathrm{C}$ & $\begin{array}{c}\text { Time flow } \\
(\mathrm{sec}) \mathrm{t}\end{array}$ & $\begin{array}{l}\text { Density } \\
\times 10^{3}\end{array}$ & $\begin{array}{c}\eta_{\mathrm{r} \text { Relative }} \\
\text { viscosity }\end{array}$ & $\begin{array}{c}\eta \mathrm{sp}=\eta \mathrm{r}-1 \\
\text { specific } \\
\text { Viscosity }\end{array}$ & $\eta_{\mathrm{r}}-1 / \sqrt{ } \mathrm{C}$ \\
\hline 0.1 & 0.31630 & 479 & 1.03607 & 2.0087 & 1.00817 & 3.18764 \\
\hline 0.075 & 0.27393 & 478 & 1.03308 & 1.99790 & 0.99790 & 3.64363 \\
\hline 0.056 & 0.23671 & 454 & 1.02907 & 1.88428 & 0.88427 & 3.73650 \\
\hline 0.042 & 0.20500 & 437 & 1.02409 & 1.80279 & 0.80279 & 3.91694 \\
\hline
\end{tabular}

TableNo8:-Dioxane-water (75\%)

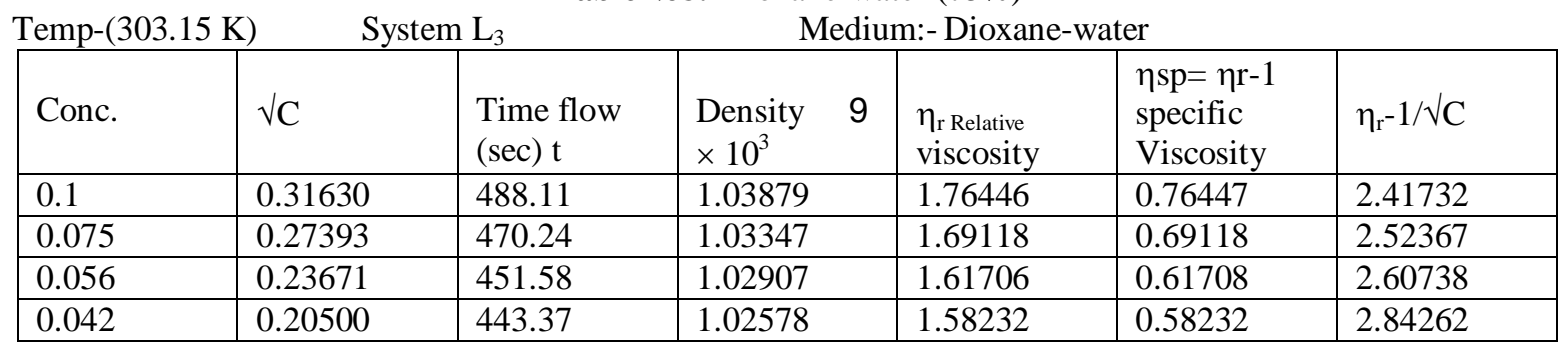

TableNo9:-Dioxane-water $(85 \%)$
Temp-(303.15 K)
System $\mathrm{L}_{3}$
Medium:- Dioxane-water

\begin{tabular}{|c|c|c|c|c|c|c|}
\hline Conc. & $\sqrt{ } \mathrm{C}$ & $\begin{array}{c}\text { Time flow } \\
(\mathrm{sec}) \mathrm{t}\end{array}$ & $\begin{array}{c}\text { Density } \\
\times 10^{3}\end{array}$ & $\begin{array}{c}\eta_{\text {r Relative }} \\
\text { viscosity }\end{array}$ & $\begin{array}{c}\eta \mathrm{sp}=\eta \mathrm{r}-1 \\
\text { specific } \\
\text { Viscosity }\end{array}$ & $\eta_{\mathrm{r}}-1 / \sqrt{ } \mathrm{C}$ \\
\hline 0.1 & 0.31630 & 504 & 1.0402 & 1.67587 & 0.67586 & 2.13714 \\
\hline 0.075 & 0.27393 & 486 & 1.0364 & 1.60972 & 0.60972 & 2.22620 \\
\hline 0.056 & 0.23671 & 474 & 1.0320 & 1.56397 & 0.56397 & 2.38297 \\
\hline 0.042 & 0.20500 & 459 & 1.0281 & 1.50989 & 0.50989 & 2.48774 \\
\hline
\end{tabular}

$\square-\beta$ Coefficient value according to Jone's -Dole Equation at different concentrations and different percentage

Temp-(303.15 K)

Table No 10:-For Ligand $\mathrm{L}_{1}$

\begin{tabular}{|c|c|c|}
\hline$\%$ Dioxane-Water & $\alpha$ - coefficient & $\beta$-coefficient \\
\hline 65 & 1.35984 & -1.8756 \\
\hline 75 & 1.09343 & -1.1537 \\
\hline 85 & 0.95267 & -1.2506 \\
\hline
\end{tabular}

Table No 11:-For Ligand $L_{2}$

Temp-(303.15 K) System $\mathrm{L}_{2}$,

\begin{tabular}{|c|c|c|}
\hline$\%$ Dioxane-Water & $\alpha$-coefficient & $\beta$-coefficient \\
\hline 65 & 1.8073 & -1.4287 \\
\hline 75 & 0.98288 & -3.0008 \\
\hline 85 & 0.95480 & 2.8757 \\
\hline
\end{tabular}


Table No 12:-For Ligand $\mathrm{L}_{3}$

Temp-(303.15 K) System $\mathrm{L}_{3}$,

\begin{tabular}{|c|c|c|}
\hline \% Dioxane-Water & $\alpha$ - coefficient & $\beta$ - coefficient \\
\hline 65 & 2.07367 & -6.0006 \\
\hline 75 & 1.53254 & -4.1307 \\
\hline 85 & 1.52702 & -3.0308 \\
\hline
\end{tabular}

\section{Result and Discussion:}

The relative viscosity of each solution during study was determined by formula depicted below $\eta_{\mathrm{r}}=\mathrm{Ds} \times \mathrm{ts} / \mathrm{D} \omega \times \mathrm{t} \omega \quad$ Where, $\eta_{\mathrm{r}}=$ Relative viscosity of ligand solution, Ds and $\mathrm{D} \omega$ are Density of ligand solution and density of water, Ts and $t \omega=$ Time of flow for ligand solution and water respectively. The relative viscosities have been analyzed by Jone's-Dole equation

$(\eta \mathbf{r}-1) \sqrt{ } \mathbf{C}=\square+\beta \sqrt{ } \mathbf{C}$ Where, $C$ is molar concentration of the ligand solution, $\alpha$-is the Falkenhagen coefficient which is the measure of solute-solute interactions and $\beta$-Is the Jones's - Dole coefficients which is the Measure of solute-solvent interactions.

The graph are plotted between $(\eta \mathbf{r}-\mathbf{1}) \sqrt{\mathbf{C}}$ versus $\sqrt{\mathbf{C}}$.The graph for each system gave linear straight line showing validity of Jone's -Dole equation. The slope of straight line gave value of $\boldsymbol{\beta}$ coefficient.

In the present study, relative viscosity of ligand solutions increases with increase in the concentrations of solute (ligand). This is due to the increase in the relative viscosity with increase in the concentration of ligand which causes much more solute -solvent interactions, and hence the viscous property of that system increases which clearly indicate that when the percentage of solute increases and hence transmission and absorption of drug decreases in this case, it means that drug activity and effect for that drug is less at higher concentration while at lower concentration these effects are good. This study attributes to increase in solute-solvent interactions and favors homeopathy therapy.

The large and small values of $\alpha$ show the stronger and weaker solute -solute interactions respectively. Solute with positive viscosity $\boldsymbol{\beta}$ coefficient are characterized as "Structure formers" and will impose a new order by reorientation of the adjacent water molecules. The $\beta$ coefficient values are positive for all the systems .This showed stronger interactions between solute and solvent .It was observed from Table No 10-12 that $\alpha$ coefficient values of $\mathrm{L}_{3}$ is comparatively more than $\mathrm{L}_{2}$ and $\mathrm{L}_{1}$. This is due to bulkier nature and unsaturation of substituent's groups present on thiourea moiety. From this study it was cleared that when the bulky group is present on ligand then solute -solvent interactions in those system increases and mobility of drug (solute) and transmission decreases .From this study, it was observed that the drug activity and effect of S-triazinothiourea drug will be increase by avoiding the substitutions of bulkier groups in triazinothiourea nucleus. This data is useful to chemist and researcher of pharmaceutical and medicinal sciences.

For the ligand $\mathrm{L}_{1}, \mathrm{~L}_{2}$ and $\mathrm{L}_{3} \square$ and $\boldsymbol{\beta}$ coefficient values were decreases with increase in percentage of dioxane -water, which indicate that solute-solvent interactions goes on decreasing due to which drug mobility and transmission goes on increasing of solvent .We can say that the drug activity and effect of Striazinothiourea drugs will be increase in higher percentage of solvent . At the same time, at $65 \%$ Dioxanewater. $\square$ and $\boldsymbol{\beta}$ coefficient goes on increasing for the ligand $\mathrm{L}_{1}, \mathrm{~L}_{2}, \mathrm{~L}_{3}$, which indicate solute - solvent interaction goes on increases at the same time mobility of drug and transmission goes on decreases. Similarly, result obtained for $75 \%$ and $85 \%$ dioxane water mixture. All the three ligand $L_{1}, L_{2}, L_{3}$, have the $\beta$ positive values which indicate that stronger interaction between solute and solvent. At lower concentration the drug activity and effect of triazinothiourea is the best.

\section{Reference}

[1] Solanki Anjani and Thakur Indrajit, Indian journal of Chem.(2006), 45B, 517.

[2] Saleem Farooq, Eur.Pot, CHAPPL, (2008), 87/19

[3] Baldaniya B.B., and Patel P.K., E-Journal of Chem., (2009) ,6(3), 673-680.

[4] Solankee Anjani and Kapadia Kishore, Indian J Chem., (2007) 46B, 1707-1712

[5] Martin.J, Borodie M., and patric Kwan, British Medical journal, (2000), 22(1), 5-7

[6] Patil S.U., Raghuwanshi P.B., Tayade D.T., J .Acta Ciencia Indica, (2007), XXXIIIC (4), $435-37$.

[7] Jain Shilpi, Bambi D., Sharma Ranjana and Talesara G.L., Indian journal of pharmaceutical science,(2007),28-32

[8] Baldaniya B.B., E-Journal of Chem., (2010), 7(1), 210-214Aswale S.S., Raghuwanshi P.B., Tayade D.T., Aswale S.R., Indian J Chem., (2007), 84,159-164

[9] Nagar S., Singh H., J.Med Chem.,(2007),16, 178-180.

[10] Jones G., and Doles M., J.Am.Chem.Soc. (1929), 51, 2950. 